\title{
ASSISTÊNCIA À POPULAÇÃO INDÍGENA: DIFICULDADES ENCONTRADAS POR ENFERMEIROS
}

INDIGENOUS POPULATION ASSISTANCE: DIFFICULTIES ENCOUNTERED BY NURSES

\author{
Natália Pereira Marinelli ${ }^{1}$ \\ Deiane Ferreira Nascimento ${ }^{2}$ \\ Alana IImara Pereira Costa ${ }^{3}$ \\ Maria Belén Salazar Posso ${ }^{4}$ \\ Layana Pachêco Araújo ${ }^{5}$
}

RESUMO: Este estudo objetivou identificar as dificuldades encontradas por enfermeiros na assistência à população indígena de Grajaú-MA. Trata-se de um estudo de corrente fenomenológica, exploratória, explicativa, com abordagem qualitativa. Foram realizadas entrevistas com os enfermeiros integrantes do Programa Saúde da Família Indígena da referida cidade. Constatou-se que entre as dificuldades estão: a falta de treinamento introdutório ao iniciar um trabalho com o indígena; dificuldade de comunicação; barreiras geográficas; aceitação do profissional por parte do indígena e condições de trabalho não satisfatórias. Há então, necessidade de capacitação prévia ao início do trabalho com o indígena e qualificação constante, englobando aspectos culturais, para que a enfermagem, por meio de um cuidado transcultural, possa atuar com efetividade.

Palavras-chave: dificuldades; enfermagem; população Indígena.

ABSTRACT: This study identified the difficulties encountered by nurses in assisting the indigenous population of Grajau, MA. This study uses a current phenomenological, exploratory, explanatory, and qualitative approach. Interviews were conducted with nurses from the Health Program for Indigenous Families of that city. Among the difficulties found are: the lack of introductory training to begin working with the indigenous, communication difficulties, geographical barriers, professional acceptance by the indigenous, and unsatisfactory working conditions. There is a need for training prior to working with indigenous people and constant qualification covering cultural aspects, so that nursing, through a transcultural care, can be effective.

Keywords: difficulties; nursing, indigenous people.

\footnotetext{
${ }^{1}$ Mestranda em Bioengenharia - Universidade do Vale do Paraíba - Univap, Docente da Faculdade de Ciências e Tecnologia do Maranhão - Facema e da Universidade Estadual do Maranhão - UEMA, Coordenadora do PET - Saúde da Família e Enfermeira da Estratégia de Saúde da Família - ESF da Prefeitura Municipal de Saúde de Caxias - MA. E-mail: enfnatmarinelli@hotmail.com.

${ }^{2}$ Enfermeira da ESF da Secretaria Municipal de Saúde de Grajaú - MA. E-mail: deianeferreira@hotmail.com.

${ }^{3}$ Coordenadora da Escola de Enfermagem Nossa Senhora das Graças em Codó - MA. E-mail: alana_ilmara@hotmail.com.

${ }^{4}$ Doutora em Enfermagem - Universidade de São Paulo - USP e Professora Integral da Univap. E-mail: mbelen@terra.com.br.

${ }^{5}$ Mestranda em Bioengenharia - Univap e Enfermeira da ESF da Secretaria Municipal de Saúde de Caxias - MA. E-mail: pacheckinha@hotmail.com.
} 


\section{INTRODUÇÃO}

A Constituição Brasileira de 1988 (BRASIL, 2000) determina que "a saúde é um direito de todos e um dever do Estado". Pode-se, então, inferir que a saúde deve ser levada, independentemente de cultura, credo ou cor, a toda a população brasileira.

A população indígena nas aldeias, segundo a Fundação de Saúde (BRASIL, 2007), é distribuída em 24 estados, 432 municípios, 336 pólos-base, 4.413 aldeias, totalizando 615 terras indígenas. A população indígena está concentrada em municípios pequenos da região amazônica, o que constitui um desafio para todos os programas do governo e sistemas de informação devido às carências infraestruturais e tecnológicas dessa região.

Em relação à essa população, os seus antepassados contribuíram com muitos aspectos de suas diversificadas culturas para a formação do que atualmente se chama Brasil, um país de vasta extensão territorial, cuja população é formada pelos descendentes de europeus, negros, índios, que mesclaram suas diferentes línguas, religiões e tradições culturais em geral, propiciando a formação de uma nova cultura, fortemente marcada por contrastes.

No Brasil, há o Sistema Único de Saúde (SUS), e mediante ele, vem-se buscando dar uma cobertura de saúde, de forma igualitária, a toda à nação, e se não bastasse isso, engloba uma "sub-nação", a indígena, considerada como tal por apresentar cultura e língua próprias (BRASIL, 2007). Decorreu desse fato a criação de um subsistema de atenção à saúde indígena, intitulado Política Nacional de Assistência à Saúde dos Povos Indígenas (PNASPI).
Pode-se observar, no cenário da saúde nacional, a Estratégia Saúde da Família (ESF) e o Programa da Saúde da Família Indígena (PSFI), que vem atuando no âmbito da saúde indígena, buscando, por intermédio das equipes multidisciplinares, proporcionar ações que venham a evitar agravos e preservar a saúde do índio. Nesse cenário, tem-se o enfermeiro que deve estar apto a prestar assistência de qualidade como é preconizado pelas políticas de saúde indígenas.

Realizou-se consulta bibliográfica sobre a população indígena, no contexto nacional e estadual, englobando aspectos sócio-culturais, aspectos referentes à sua saúde; e a inserção da enfermagem como prestadora de assistência nessa questão. Vários questionamentos surgiram, tais como: qual é a atuação da enfermagem nesse cenário? Existem dificuldades para desenvolver a assistência a essa população? Se realmente elas existem, como ocorre 0 enfrentamento das dificuldades pelos enfermeiros? Como se dá a aceitação por parte da população indígena? Esses questionamentos levam à reflexão sobre como é "o trabalhar com o índio", sobre o "estar ou não preparado" para enfrentar esse desafio.

Tendo em vista esse contexto, este trabalho pretende criar subsídios para que sejam feitas reflexões acerca do tema, e possivelmente propor estratégias para que se dispense uma assistência de qualidade à população indígena, contribuindo, assim, com a classe de enfermeiros que prestam cuidados a esse grupo. 


\subsection{A comunidade indígena de Guajajara em Grajaú-MA}

Pode-se, resumidamente, afirmar que a história recente dos Guajajaras é marcada pela participação ativa na luta pelos seus direitos, seja no que diz respeito à política do órgão tutor, seja na participação ativa na sociedade regional.

A principal atividade econômica de subsistência desse povo é a lavoura. Algumas aldeias têm grandes roças comunais. A pesca é mais praticada pelas aldeias ribeirinhas. A caça e a coleta ainda são bastante praticadas por muitos dos Guajajaras.

Segundo Zanonni (1999), os Guajajaras eram inicialmente denominados Tenetehara. Não se sabe ao certo a origem do nome Guajajaras, mas provavelmente foi dado aos Tenetehara pelos Tupinambás, que foram os primeiros indígenas a habitarem o Maranhão.

No que diz respeito à organização social e política, atualmente as aldeias não mais tomam uma forma típica, segundo Grupioni et al. (2001). São compridas, ao longo de caminhos, redondas ou quadrangulares, localizam-se, preferencialmente, perto de rios ou lagoas na mata.

A sociedade Guajajaras, estrutura-se a partir da "família extensa", que é composta por um número de famílias simples, unidas entre si por laços de parentesco. Essa se constitui pelo casamento realizado entre filhas de chefes de uma família, e parceiros de outras (ZANONNI, 1999, p. 97).

Os Guajajaras produzem, como cultura material, cestarias, arte plumaria, adornos e armas, e se utilizam de pinturas corporais para ocasiões de festas e rituais, e manifestações políticas. Os Guajajaras têm forte cosmologia, mitos e ritos em sua história, os quais são observáveis, ainda, nos dias atuais. Um dos ritos que se pode observar e que marca fortemente a cultura indígena Guajajaras é a festa do moqueado, ou festa da menina moça (GRUPION et al., 2001).

A função do Pajé, na aldeia, é reconhecida também pela própria Funasa, que estimula a participação das parteiras e dos pajés na EMSI (Equipe Multidisciplinar de Saúde Indígena), com acesso à remuneração e aos direitos trabalhistas (BRASIL, 2007).

No que diz respeito à educação dos Guajajaras, Cruz (2007) cita que a situação da educação encontra-se um pouco melhor que há décadas. A escola é bilíngue, embora algumas não tenham estrutura para tal, seja por parte financeira, ou por qualificação profissional insuficiente.

\section{OBJETIVO DO ESTUDO}

Identificar as dificuldades encontradas por enfermeiros na assistência à população indígena em Grajaú-MA.

\section{METODOLOGIA}

Trata-se de um estudo que se utiliza da corrente fenomenológica, com uma abordagem qualitativa, de cunho etnográfico, descritivo-exploratório, desenvolvido no município de Grajaú Maranhão, localizado ao Sul do estado, às margens da BR 226 a $580 \mathrm{Km}$ da Capital São Luis, pertencendo à mesorregião Centro maranhense, e microrregião do Alto 
Mearim e Grajaú. O município conta com uma área de $7.407,824$ km², e população de 54.135 habitantes (IBGE, 2007).

É uma cidade entrelaçada fortemente com a cultura indígena, visto que possui reservas indígenas dentro e nas proximidades da cidade, com 66 aldeias totalizando 5.651 índios (DISTRITO SANITÁRIO ESPECIAL INDÍGENA-MA, 2009).

A pesquisa foi realizada segundo os princípios e normas regulamentadoras de pesquisa envolvendo seres humanos, Resolução 196/96, Conselho Nacional de Saúde - Ministério da Saúde, sendo encaminhada para o Comitê de Ética e Pesquisa (CEP) da NOVAFAPI, em Teresina - Piauí, em 09 de março de 2010, tendo sido analisada e aprovada com parecer favorável.

Após aprovada pelo CEP, foi encaminhado um ofício de formalização de pesquisa para a chefia de cada sub-pólo indígena, responsável pelo PSFI de suas aldeias, e, após permissão, iniciou-se a pesquisa com apresentação do Termo de Consentimento Livre e Esclarecido aos participantes, no qual foi explicado, nessa oportunidade, o seu conteúdo, e, posteriormente, assinado pelos que aceitaram participar da pesquisa.

Como critérios de seleção para participar do estudo, os indivíduos deveriam ser enfermeiros, atuar, atualmente, na assistência a indígenas Guajajaras em Grajaú-MA, ser profissional do quadro do PSF, e aceitar participar da pesquisa. Assim, selecionaram-se 06 (seis) enfermeiros das equipes que atuam em Grajaú - MA.

Os 06 (seis) enfermeiros são, doravante, identificados da seguinte da forma, para resguardar e garantir 0 anonimato: E 01, E 02, E 03, E 04, E 05, E 06. As entrevistas semi-estruturadas foram guiadas por um instrumento do tipo formulário, composto por questões norteadoras sobre os motivos que levaram o enfermeiro a trabalhar no PSFI; sua prática profissional nesse Programa; as dificuldades encontradas na assistência à população indígena e seu enfretamento frente a essas dificuldades.

Todas as entrevistas ocorreram em horários previamente agendados com os enfermeiros, em suas residências, de acordo com sua preferência e disponibilidade, por ser mais confortável e permitir livre expressão do sujeito, com total privacidade. As entrevistas foram gravadas, transcritas na íntegra e submetidas à apreciação dos entrevistados para garantir a maior fidedignidade às respostas, e, após exaustivas leituras do conteúdo, as ideias emitidas foram agrupadas e categorizadas de acordo com a análise temática (BARDIN, 1977; MINAYO, 2004), e com o objetivo proposto.

Esse referencial (BARDIN, 1977; MINAYO, 2004) permite descobrir os núcleos dos sentidos que compõem as evidências comunicadas, cuja presença ou frequência apresentam significado para a compreensão do discurso. Obteve-se, então, temas que emergiram da análise das informações referentes às dificuldades, opiniões, atitudes, valores, entre outros aspectos. A seguir realizaram-se três etapas: a pré-análise, primeiro contato com 0 conteúdo perviamente conferido pelos atores, favorecendo a organização do material; em seguida, procedeu-se à exploração do material, agrupando-se as respostas para identificar as congruências das falas, e a partir daí, foram elaboradas 
unidades temáticas para se chegar à terceira etapa, ou seja, ao tratamento dos resultados.

\section{RESULTADOS E DISCUSSÃO}

Após a análise do material, emergiram núcleos de significados que facilitaram a compreensão do discurso dos enfermeiros sobre a assistência à população indígena de Guajajaras em Grajaú - MA, assim como as dificuldades encontradas e 0 seu enfrentamento.

\subsection{Motivos que levaram o enfermeiro a trabalhar no PSFI}

\subsubsection{Desejo em trabalhar com o indígena}

Quando se fala em profissão, vem-se à mente a ideia de vocação, que, de acordo com Ferreira (2000), está relacionada à tendência, talento e aptidão. A realização profissional muitas vezes está diretamente ligada à admiração, desejo e ao prazer pelo que se exerce, levando o profissional a seguir o caminho que lhe é aprazível, como revelam os seguintes relatos:

E 4: "...primeiro eu comecei com o índio, eu sempre tive vontade!”

E 2: "Assim que eu me formei, eu procurei atividades fora dos grandes centros ...eu sempre gostei. Pra mim trabalhar com eles é assim diferente, uma coisa nova".

Essas falas encontram ressonância com o relato de experiência de Marroni e Faro (2004) com a população indígena:

O interesse em estudar os índios confunde-se com minha própria história de vida. Nasci e vivi onde existe a maior reserva indígena da tribo Kaigang. Cresci convivendo com aquelas pessoas 'diferentes', e perguntava-me porque eram diferentes, sem encontrar as respostas que me satisfizessem completamente. Saí do sul para estudar e trabalhar. Fiz especialização em Saúde Pública com a expectativa de poder desenvolver um trabalho junto a esta população. Comecei a trabalhar com os Índios, em um trabalho conjunto com a Fundação Nacional de Saúde (FNS) e Fundação Nacional do Índio (FUNAI) (MARRONI; FARO, 2004, p. 2).

O trabalho com as populações indígenas chega a ser atraente e digno de admiração por alguns, devido às suas peculiaridades, despertando, assim, o desejo, seja por afinidade, ou curiosidade pelo novo.

\subsubsection{Uma questão de oportunidade}

Além da vontade de se trabalhar com esse determinado grupo, há, também, casos em que a admiração prévia pode não existir, porém as oportunidades de emprego, quando ofertadas, são encaradas como novos desafios e chance de crescimento profissional. Observa-se essa oportunidade nos depoimentos abaixo:

E 1: "era o único trabalho que tava faltando pro meu currículo, (risos), um trabalho com a comunidade indígena..."

E 3: “...não tive nenhuma experiência, só curriculares mesmo, logo depois que me formei já estava atuando como enfermeira do PSFI". 
Lendo e interpretando o que foi dito pelos profissionais, pode-se inferir que 0 trabalho com essa população deu-se, na primeira fala, por interesse em relação à sua trajetória como enfermeiro, sendo uma oportunidade de tornar mais atrativo seu histórico profissional. $\mathrm{Na}$ segunda fala, observa-se que o trabalho com o indígena surgiu como oportunidade de primeiro emprego e não algo buscado como meio de realização profissional.

A motivação principal pela escolha da profissão de Enfermagem pelos acadêmicos, de acordo com Bouéri et al. (2006), é a vocação, seguido pelo reconhecimento social, profissional e salário. Porém, quando se trata de escolha de campo de atuação para exercer sua profissão, nem sempre essa ordem é seguida.

Segundo Domenico e Ide (2006), muitas vezes as expectativas estão mais voltadas a uma busca por uma melhor colocação profissional e remuneração salarial que pela satisfação profissional.

\subsection{Aprendendo a trabalhar com o índio}

O índio, na sua singularidade étnicocultural, requer cuidados específicos e qualificados. Smeltzer e Bare (2005) afirmam que o cuidado de enfermagem deve ser culturalmente competente, apropriado e sensível às diferenças culturais.

Os relatos a seguir apontam a maneira como o enfermeiro está se moldando para assistir o indígena.

\subsubsection{Aprendendo na prática}

E 4: "fui nua e crua, assim sem saber, só com os conhecimentos da faculdade... primeiro dia já me levaram pra aldeia... quando eu cheguei lá, peguei um monte de apostila dos índios, aí comecei a ler..."

E 5: "...quando eu comecei a trabalhar com índio eu não tinha nem noção de onde estava entrando... entrei nua e crua! Sem ter a mínima noção do que eu iria fazer... não tinha direção!"

Nas falas acima, percebe-se que o enfermeiro não goza de um direito seu como componente da EMSI, que é a capacitação, que visa à mútua compreensão das diferenças culturais e o respeito às práticas de saúde tradicionais de ambas as populações para exercer tal função, contrariando o disposto no relatório final da 4ª Conferência Nacional de Saúde Indígena:

Caberá à Funasa prover as EMSI de conhecimentos antropológicos e culturais, por meios de cursos, palestras, oficinas, seminários, e encontros para qualificar a assistência aos usuários indígenas com eficácia e respeito às práticas tradicionais de cada etnia (BRASIL, 2007, p. 131).

Também, segundo Alencar (2006), a formação acadêmica deve promover uma verdadeira articulação entre a educação e os serviços de saúde, valorizando as relações existentes no cotidiano do trabalho. Porém, na realidade não é o que se vê, principalmente em respeito às populações indígenas.

\subsubsection{Observando os colegas de trabalho}

Sem capacitação, uma estratégia usada pelos enfermeiros foi buscar a ajuda 
de quem já trabalha, ou trabalhou na área, como meio de se informar e se familiarizar com seu campo de atuação.

E 1: “...eu fiz o curso de PSF, mas não o específico para trabalhar com o PSFI... eu sempre dialogava com uma amiga que já tem 10 anos que trabalha com índios, mesmo sabendo mais ou menos como é que era a realidade, tive que conversar com essa colega".

E 3: “...como lá funcionam duas equipes, eu sempre tive ajuda da outra enfermeira, que me falou como é que é a rotina do trabalho, me explicou a forma de lidar com eles ...esta foi a maior capacitação que eu tive!"

Ao se explorar os depoimentos, notase que, apesar do despreparo na vida acadêmica e ainda não recebendo qualificação pelo órgão competente, os enfermeiros empenham-se em aprender a respeito do trabalho com o indígena, seja por meio da literatura, pela prática diária ou com experiência de colegas, sendo comprovada, novamente, a necessidade de uma capacitação prévia dos profissionais para se trabalhar com o povo indígena, como bem determina o relatório final da $4^{a}$ Conferência Nacional de Saúde indígena (BRASIL, 2007).

Pode-se ratificar essa afirmação com o apresentado por Cosenza e Tosta (2004), em seu estudo com indígenas do Distrito Federal, quando Ihes foi indagado sobre o atendimento recebido dos profissionais da saúde. As falas seguintes reafirmam a necessidade de priorização da educação continuada, com uma visão holística dos fatores determinantes do processo saúdedoença e qualificação profissional para esse grupo étnico:
[...] uns índios disseram que necessitam de atendimento por profissionais capacitados e que deveria existir maior entendimento das diferenças culturais, alguns citaram que deveria haver intérpretes (COSENZA; TOSTA, 2004, p. 42).

\subsection{Dificuldades encontradas na assistência à população indígena}

\subsubsection{Cultura}

Com botas de plástico e mochila nas costas, e muita loção repelente, distante do conforto de um hospital, encontra-se a enfermagem preocupada com a saúde indígena (GOLIN, 2007, p. 6).

Muitos entrevistados apontaram a cultura como dificuldade, sendo aí englobados os mitos, costumes, e crenças, expressados nas falas de cada depoente.

E 2: "Ah, questão de pajelança, isso aí na cultura indígena é horrível, ih... adoeceu diz que foi karaí, e karaí é macumba, jogaram macumba, aí geralmente levam primeiro pro pajé, aí depois que levam pro hospital, mas dificilmente eles querem ir pro hospital".

O mundo Guajajaras é sustentado por esse complexo religioso, que dirige a vida e as atividades, sendo a pessoa parte dele e deste dependendo diretamente. Para esse povo, qualquer tipo de enfermidade está relacionado com algum tipo de feitiço, que entra no corpo da pessoa e manifesta-se como doença (ZANNONI, 1999).

E 4: "Eles são tímidos, eles não chegam a você, eles ficam sempre recuados! ...Tem as crenças deles, só que a 
gente não pode mudar, a gestante, se ela ganhar neném, elas não comem frango, galinha, feijão, e tem coisas que a gente não pode impor ou não dar a importância que eles dão".

Leininger (1991), em sua teoria da enfermagem transcultural, discorre que as pessoas de cada cultura não apenas podem saber e definir as formas nas quais experimentam e percebem seu mundo de atendimento de enfermagem, mas também, podem relacionar essas experiências e percepções com suas crenças e práticas gerais de saúde. A autora retirou da Antropologia o componente cultural, e da Enfermagem o componente cuidado.

Segundo George (2000), o cuidado cultural é o meio complexo mais amplo para conhecer, explicar, interpretar e prever o fenômeno do cuidar visando a orientar a prática de cuidados de enfermagem.

E 5: “...a consulta não é uma consulta individual, é uma consulta coletiva, quando eles chegam, chegam com a família todinha, às vezes vem com o pajé, e um termina sabendo as coisas do outro, e isso aí, também interfere nas perguntas, e aquela situação pra mim também é muito constrangedora!"

De acordo com esse depoimento, outra dificuldade verbalizada ao analisá-lo é a questão da consulta coletiva, o que impede uma relação profissional-paciente mais estreita, podendo ser rompida pela vergonha dos demais.

A consulta de enfermagem é considerada uma atividade importante no intercâmbio de conhecimentos e na interação tu/eu, uma vez que apresenta um componente educativo no momento de sua realização (ALENCAR 2006).

\subsubsection{Condições de trabalho}

As falas também revelaram a necessidade de melhores condições de trabalho que, não estando presentes, ou, mesmo sendo deficientes, podem resultar em um trabalho não satisfatório tanto para os profissionais quanto para os assistidos por eles.

E 1: "[...] Nunca dormi na aldeia por que não tem condição! Nem condições de trabalho, não tem água, energia, às vezes tem, outras não tem, você tem que levar sua água pra lavar suas mãos. É ruim porque a gente não consegue fazer um trabalho que imaginava".

E 4: “...não tem equipamento pra examinar, verificar bcf, até aparelho de P.A, falta balança pra pesar criança... fica difícil da gente ir lá, por causa do material que não tem, já chegou época de eu fazer quase deitada a prevenção".

Essa fala remete a um sentimento quase que de impotência frente à situação relatada, refletindo uma frustração do profissional por não realizar o que é planejado para implementar a assistência. Como está disposto no relatório final da $4^{\mathrm{a}}$ Conferência Nacional de Saúde Indígena: "cabe à FUNASA garantir apoio logístico para maior permanência das EMSI nas aldeias com atendimento diferenciado aos índios, fornecendo aos profissionais, informações sobre cultura indígena" (BRASIL, 2007, p. 78), o que tornaria mais favorável 0 desenvolvimento de uma assistência de real qualidade $e$ resolubilidade. 
4.3.3 Barreira linguística - Comunicação e linguagem

A comunicação é primordial para uma assistência direcionada às necessidades do paciente e quando esta é prejudicada pode gerar uma inadequação de assistência, como foi revelada pelos depoimentos a seguir.

E 2: "Com relação à linguagem, ainda hoje sinto dificuldade, só que assim, eu já entendo bastante coisa... tem alguns deles que não falam direito a nossa língua, e eles ficam calados. Então, a gente vai perguntando: RAKU: febre, URW: vômito, PIARARRY: diarréia... se a gente for perguntar: Desmaiou? Eles afirmam: Desmaiei!, às vezes nem desmaiou, então, é necessário ter realmente um intérprete ".

E 5: “...eles falavam uma coisa eu entendia outra... se eles perguntam na linguagem deles e você responde na linguagem deles eles ficam muito felizes ...Eu mesmo tenho medo de dar palestra, porque eu falo uma língua e eles falam outra, quem trabalha com índio tem que ter muito cuidado ao falar".

Sem entender a língua, os equívocos são frequentes, tem-se trabalhado essa diferença e essa dificuldade ao longo da história (GRUPIONI et al., 2001). E, parafraseando George (2000), pode-se ressaltar que diferenças notáveis entre os significados e as expressões dos prestadores e dos receptores de cuidado levam à insatisfação de ambos. Alencar (2006) frisa que o diálogo é um caminho fundamental para que ocorra a construção e a troca dos saberes.

A diferença linguística que separa a classe de profissionais do PSFI dos seus assistidos gera déficit de comunicação e está claramente relacionada à cultura do povo em questão. Cultura esta que se explica na timidez e na dificuldade em expressarem fatos que certamente contribuem para a pouca interação entre o binômio enfermeiro - paciente, culminando em uma relação frágil e pouco concreta.

\subsubsection{Dificuldade no acesso/barreira geográfica}

Além da deficiência nas condições de trabalho, referindo-se à falta de estrutura, encontrou-se, também, as dificuldades de acesso físico, que torna ainda mais delicado o trabalho com indígenas, pois há uma verdadeira jornada para chegar ao local de trabalho, como comprovam as falas a seguir:

E 4: "...outra dificuldade, é chegar até a aldeia, com certeza! A gente passa quase duas horas pra chegar nas aldeias, na última a gente chega depois de um trajeto de umas três horas".

E 6: "...a gente atende aldeia depois do Arame, a gente atende aldeia em cima de morro, você sobe o morro, e quando chega lá, tem que esperar uma meia hora para começar a falar. A gente atende em aldeia que é preciso a gente passar por dentro de lago, passar por dentro de rios, mas, eu gosto!

Golin (2007) afirma, que como se não bastasse a adequação ao ambiente (caminhada longa mata adentro, sol e chuva) também são necessárias coragem, disposição e motivação.

O profissional tem que vencer 0 cansaço para prover os atendimentos necessários com qualidade e especificidade, o que torna ainda mais precioso tal trabalho, devendo, assim, ter o merecido 
reconhecimento, não só pelo esforço que requer, mas pela dedicação com que é realizado.

4.3.5 Aceitação do profissional pelo indígena/confiança

Outra vertente que surgiu a respeito das categorias dificuldades foi a de aceitação do enfermeiro pelo indígena, aceitação esta que implica na confiança do paciente em relação ao profissional, retratada nas frases abaixo:

E 2: "...como eu fui "nova", vamos dizer assim, eles sentiam alguma coisa, chegavam até o posto, e falavam com as meninas, nem olhavam pra mim, eles acham também que a gente tirou a antiga enfermeira, eles acabam criando um vínculo e um carinho muito grandes!".

E 5: “... é bem difícil você adquirir a confiança deles, quando eles gostam da pessoa, gostam mesmo... e se for preciso eles vão lá brigar... eu quero meu "enfermerim" de volta!".

Em um trabalho realizado por Cruz (2007) sobre ações afirmativas dos povos indígenas, encontram-se citações sobre fatos ocorridos no período de 2002 a 2006, somando-se mais de trinta situações em que os Guajajaras acionaram as estratégias indígenas, tentando participar das decisões relativas à saúde indigenista no DSEI-MA, entre eles, o gerenciamento dos serviços e recursos financeiros para as ações de saúde e o gerenciamento dos recursos humanos, além de denúncias específicas sobre qualidade dos serviços indigenista de saúde. Afirma, ainda, que os Guajajaras utilizaram essas estratégias alternativas como forma de pressionar os órgãos competentes no atendimento às suas demandas.
4.3.6 A resistência de assistência por gênero

Nessa categoria, retratou-se a dificuldade de assistência por gênero, principalmente a resistência do índio em deixar a esposa realizar exame preventivo, sendo ainda mais difícil se for um profissional do sexo masculino. As falas também ressaltaram a forte presença do homem índio em meio à cultura desse povo.

E 1: "Por eu ser homem, tem dificuldade na questão de se trabalhar saúde da mulher, na hora de fazer os preventivos, aí a gente até conversou com as auxiliares, pra gente treinar, para elas fazerem os preventivos".

E 4: "...os índios homens tem ciúmes da mulheres, então, em relação à prevenção, eles não deixam, ainda mais se for enfermeiro homem, com a mulher não, eles já se aproximam mais".

Depreendeu-se que o gênero tem significante influência na cultura Guajajaras, o que refletirá no cuidado prestado, ou seja, a não aceitação do enfermeiro do sexo masculino pelo indígena dificulta as ações voltadas à realização do exame citológico para a prevenção de câncer de colo de útero, tão importante à saúde da mulher.

E 3: "nas consultas quem fala é o esposo. Elas falam na língua deles, e eles repassam pra gente, e ele se sente um protetor... ele tá ali, é ele quem impõe as regras, é ele que fala, é ele que expõe o que a mulher ta sentindo."

Pode-se inferir que, para os Guajajaras, o homem tem lugar de destaque, pois o nascimento de uma criança do sexo masculino é festejado com alegria, o mesmo não acontecendo com o nascimento de uma menina (ZANNONI, 1999). 


\subsection{Vencendo os obstáculos}

Nessa categoria, podem-se observar as atitudes dos enfermeiros frente às dificuldades e ações que realizam para enfrentá-las, vencê-las ou minimizá-las, visando à melhor assistência, como mostram os depoimentos a seguir:

\subsubsection{Um olhar holístico do indígena}

Quando indagados a respeito do enfrentamento das dificuldades, verificou-se que os enfermeiros procuram desenvolver um cuidar holístico, na tentativa de superálas.

E 2: “...assim, tem que agir naturalmente! tem que tentar ouvir os problemas desse paciente respeitando seu modus vivendi...".

E 3: "Você tem que saber atender as pessoas com igualdade, se você tá lá com o indígena, você tem que saber falar da forma que ele vai compreender, se você tiver que falar a palavra mais rústica, mais popular, você tem que falar, por que é a única forma de compreensão que ele tem ...Então, o que eu faço é isso, é tentar compreender e fazerme compreender".

A expressão oral dos profissionais enfatiza uma assistência voltada para a igualdade, mas não esquecendo que a equidade leva em consideração as desigualdades existentes, e deve ser adaptada ao se trabalhar com indígenas, abordando as peculiaridades culturais e linguísticas que o enfermeiro deve conhecer a priori.

Os sistemas tradicionais indígenas de saúde são baseados em uma abordagem holística, cujo princípio é a harmonia de indivíduos, famílias e comunidades com o universo que os rodeia (BRASIL, 2002).

E6: "Quando eles vão ao pajé, a gente tenta falar pra eles, a gente explica pra eles a doença... só que eles vão ao pajé e fazem o que ele manda, mas, todas as vezes esses pacientes voltam".

Não se pode impedi-los de negar a aceitação do nosso cuidado, mas, pela educação em saúde, pode-se tentar fazê-los entender a importância desse cuidado. Reportando à ideia de George (2000), devese lançar mão do ajustamento ao cuidado cultural, também conhecido como negociação, incluindo as ações de decisões profissionais criativas, apoiadoras, facilitadoras ou capacitadoras que ajudam as pessoas de uma determinada cultura a adaptarem-se ou a negociarem com as outras um resultado de saúde benéfico ou satisfatório.

4.4.2 Usando a criatividade no atendimento ao indígena

Em algumas ocasiões, pôde-se observar que o profissional, utiliza-se da arte de criar, para que a assistência possa ser possível, mesmo quando as condições apontavam o contrário.

E 5: “...a gente vai fazer essas consultas nas aldeias fora do posto de saúde, a gente cria condições de consulta debaixo da mangueira, na carroceria do carro, em qualquer lugar... a gente faz os atendimentos de saúde nas festas indígenas, nos eventos, você faz entrega de camisinhas, é..., coleta de material..."

E 6: "a gente tem que comprar o material, todo nosso material de trabalho, de base, comprar o medicamento, tem que criar a parte da organização, é a gente que 
compra e a gente improvisa na verdade, né!"

Com as explanações anteriores, verificou-se que a enfermagem na atuação em área indígena, assim como em qualquer outra área, utiliza o instrumento básico de enfermagem, a criatividade, entre outros, que, segundo Ferreira (2000), significa adaptar, inventar de repente, compor sem preparação, arranjar às pressas, construir com material não apropriado, ou seja, característica que esses profissionais têm como um dom e é trabalhado na sua Graduação.

É notório, em seus atos, mais que compromisso, a boa vontade e desejo de, apesar das limitações, prestar uma assistência de qualidade. O trabalho da equipe de enfermagem exige algumas peculiaridades que vão além da parte técnica da profissão.

É preciso bom humor, bom relacionamento, observação aguçada, habilidade psicomotora e de comunicação, espírito e trabalho de equipe, flexibilidade no planejamento (GOLIN, 2007).

\section{CONCLUSÃO}

A enfermagem, no contexto da saúde indígena, não mede esforços para prover os cuidados, vencendo barreiras étnicas, culturais, geográficas, linguísticas e de comunicação, que se constituem, muitas vêzes, como desafios para prover os cuidados.

Durante a pesquisa, os depoimentos demonstraram que há um número relevante de dificuldades encontradas por esses profissionais em atender uma população tão peculiar.

Por meio dos resultados, pôde-se constatar, também, que, não bastassem os obstáculos já citados, outra dificuldade sentida pelos enfermeiros é a falta de capacitação prévia ao trabalho com o índio Guajajara. A ausência desse preparo proporciona ao profissional um sentimento de insegurança referente à assistência que deverá prestar.

Observa-se que, apesar de existirem políticas e programas que pareçam ter aumentado 0 acesso do indígena à assistência e ações preventivas de saúde não estão sendo implementados como previsto, como evidenciaram as falas dos entrevistados, por meio das dificuldades encontradas durante a assistência, que vão além do fator cultural.

Vê-se, então, a real necessidade de realização de capacitação prévia, e educação constante ao enfermeiro que destinará seu cuidado ao indígena, sendo esses fatores relevantes, no que diz respeito à qualificação da assistência, para que ele seja, então, competente, em relação a aspectos culturais, embasados em conhecimentos antropológicos.

Contudo, pode-se concluir, então, que, apesar de todas as dificuldades, a enfermagem mostra-se presente e atuante, disposta a reaprender o cuidar, tornando este moldável para atender às peculiaridades e especificidades do homem índio, e para destiná-lo a público tão necessitado de saúde e merecedor desse cuidar, como qualquer outro, de forma eficaz e suficiente.

Espera-se que este estudo sirva a reflexões acerca da assistência a esse povo - o indígena -, assistência que deve ser de qualidade, atendendo às peculiaridades indígenas. Espera-se, também, que outros estudos sejam feitos abordando a temática desta pesquisa. 


\section{REFERÊNCIAS}

ALENCAR. R. C. V de. A vivência educativa do enfermeiro no Programa Saúde da Família (PSF). 2006. 122f Dissertação (Mestrado em Enfermagem). Escola de Enfermagem. Universidade Federal de Minas Gerais, Belo Horizonte, 2006.

BARDIN, L. Análise de conteúdo. Lisboa: Edições 70, 1977.

BRASIL, Constituição (1988). Constituição da República Federativa do Brasil: 1988. Brasília, Câmara dos Deputados, 2000.

Ministério as Saúde/ Secretaria de

Políticas de Saúde - Departamento de Atenção Básica, Coordenação de Estratégia para 0 Desenvolvimento e gestão da Atenção Básica. Portaria n.ำ 245/GM, em 31 de janeiro de 2002.

Fundação Nacional de Saúde. $4^{a}$ Conferência Nacional de Saúde indígena, Rio Quente-GO, relatório final. Brasília: Funasa, 2007.

BOUÉRI, A. T. et al. Perspectivas dos acadêmicos de enfermagem em relação ao mercado de trabalho. 2006. Monografia. (Trabalho de Conclusão do Curso de Enfermagem) - Universidade Paulista (UNIP), São José dos Campos-SP, 2006.

COSENZA, L. F.; TOSTA, R. B. Avaliação da capacitação de recursos humanos de rede de referencia do DF para o atendimento a população indígena. 2004. Monografia (Especialização em Odontologia em Saúde Coletiva) - Associação Brasileira de Odontologia, Brasília, DF, 2004.

CRUZ, K. R. da. Povos indígenas, saúde e ações afirmativas: Universalidade $e$ diversidade como desafios. In: Anais do XIII Congresso Brasileiro de Sociologia; 2007, 29 mai-01 jun; Recife (PE): Universidade
Federal de Pernambuco, Brasil 2007.

DISTRITO SANITÁRIO ESPECIAL INDÍGENA-MA (DSEI). Censo vacinal 2009. São Luis: FUNASA, 2009.

DOMENICO, E. B. L.; IDE, C. A. C. As competências do graduado em enfermagem: percepções de enfermeiros e docentes. Acta Paulista de Enfermagem, v. 19, n. 04, São Paulo, out./dez. 2006

FERREIRA, A. B. de $\mathrm{H}$. et al. Miniaurélio século XXI: $O$ mini dicionário da língua portuguesa. 4 ed. Rio de Janeiro: Nova Fronteira, 2000.

GEORGE, J. B. Teorias de enfermagem: os fundamentos a pratica profissional; 4. ed. Porto Alegre: Arets Médicas Sul, 2000.

GOLIN, R. A Enfermagem Preocupada com a Saúde Indígena. Rev. Coren, n. 72, p. 6-9, São Paulo: COREN, 2007.

GRUPIONI, L. D. B. et al. Povos indígenas e Tolerância: Construindo práticas de respeito e Solidariedade. São Paulo: Universidade de São Paulo, 2001.

IBGE. Instituto Brasileiro de Geografia e Estatística. Apresenta informações sobre dados demográficos da cidade de GrajaúMA, 2007. Disponível em: http://www.ibge.gov.br/cidadesat/topwindow. htm?1Grajau-MA. Acesso em: 28 out. 2009.

LEININGER. M. M. Care: The compassionate hearler. New York: National lealgue for nursing. (1991).

MARRONI, M. A.; FARO, A. C. M. E. Siendo enfermera de los indios: relato de la experiencia sobre el cuidado del indio en el Sur de Brasil. Enfermería Global, Portugal e Espanha, v. 1, n. 5, p. 1, 2004.

MINAYO, M. C. S. O desafio do Conhecimento: Pesquisa Qualitativa em 
Saúde. 3. ed. São Paulo: Hucitec-Abrasco, cirúrgica. Rio de Janeiro: Guanabara 2004. Koogan, 2005.

SMELTZER, S. C.; BARE, B. G. Brunner e ZANNONI, C. Conflito e Coesão: o Suddarth, Tratado de enfermagem médico- dinamismo tenetehara. Brasília: Conselho. 